\title{
What Lead to the Successful Mobile Phone Game? - Story of birds who cannot fly but they have enough angriness
}

\author{
Yang Liu \\ Department of Production, University of Vaasa \\ Address: Wolffintie 34, 65200, Vaasa \\ E-mail: yli@uva.fi
}

Jaakko livonen

Department of Production, University of Vaasa

E-mail: iivonenjaakko@gmail.com

\begin{abstract}
This article will consist of analyzing some factors which are the most important for the successful mobile phone game. There are going to be some common history of how mobile phone games are developed and how this whole game application business has started. Main focus in this article is based on analyzing and finding some key factors which are the most relevant for successful mobile phone game and how they can be designed. This article is not based on technical details of mobile phones and there is only some information which consists of a little bit of technical phrases. Angry Birds mobile phone game is excellent example of successful mobile game and it will be analyzed rather deeply in this article. Analyzing will not be based on only how to play game but whole Angry Birds phenomenon will be considered. Developments of mobile phone games have been very fast even though the first and nowadays classic mobile phone games (such as Snake) become in 1970s. Last year has been golden age for mobile phone game designers and this business area is still developing very fast. Rovio Entertainment is one of the winners so far. Since few years ago Rovio was close to bankruptcy and nowadays it is globally known entertainment media company. Rovio is behind the Angry Birds which is the most popular mobile phone game.
\end{abstract}

Keywords: Angry Birds, Iphone application, mobile phone game, Rovio Entertainment 
What Lead to the Successful Mobile Phone Game?

- Story of birds who cannot fly but they have enough angriness

\section{INTRODUCTION}

Designing successful mobile phone game may sound very simple task because smartphones does not offers very high technique to play the games. This is the tricky point when designers had to focus on create something especially which is at the same time very simple. Characters behind one of the most successful mobile phone game (Angry Birds) ever are birds whose are not able to fly or walk. This sounds as simple as it can ever be but how they can be so attractive and addictive to become global phenomena and spread to other business areas too.

This article is focused on analyzing why some of the mobile phone games are successful and some other does not have similar success. Aim of the article is to find if there are some elements which are repeated in successful games or are they just so well created. The first mobile phone games and even nowadays still many of them are not designed for smartphones. Normally games are designed to other game platforms such as personal computer or game consoles before and afterwards game designers are just copied or modified games to work in smartphones. One of the best known mobile phone games ever is the Snake which was released in Nokia 6110-model. Nowadays the Snake is a classic mobile phone game but its history is similar as many other games too that it was firstly designed to be player by personal computer.

After the most of the mobile phones become smartphones also game designers realize that games are not so easy to modify from other platform to smartphones. Touch screens are one of the biggest reasons for this because control commands are so different when using touch screen comparing to buttons. Also at least some of the designers have realized that mobile phone games must be designed straight to smartphones if they want the game become successful. Other important element for mobile phone game is gamers profile and when and where those games are played. Normal mobile phone gamer is not willing to spend lots of time to learn how to play and they are not willing to watch tutorials before they can start playing the game. Mobile phones applications are used approximately less than one minute at the time so gamers are not willing to use lots of time for loading games. Also games cannot be based on some story because games concentration to play the game is not very high. Normally games are played when smartphone users are waiting something or they just have some extra time. Mobile phone games are not played similar as console games are when players focus is totally on game.

Angry Birds mobile phone is the one of the most popular game applications ever. Idea of game is very simple and player will achieve high results with a little bit of work when game will be addictive. Angry Birds is easy to learn and it can be played in very short-term. Nowadays Angry Birds is not anymore only successful mobile phone game, it is something bigger. It is phenomena spreading in many other business areas also and only future will show us what kind of new things Angry Birds will be. Creators behind Angry Birds have told in many times that their dream is to be bigger that Disney. They want that Angry Birds is in future Disney 2.0. This is a huge dream and will it ever come true is something nobody knows at the moment but Angry Birds is already conquer so many areas and people hearts so why not.

\section{DEVELOPMENT OF MOBILE PHONE GAMES}

History of mobile games reaches over ten years, even there have been portable game devices since 1970s. Nokia released new 6110 - mobile phone in 1997. New mobile phone has also Snakegame, which is nowadays classic game and Nokia has estimated in year 2005 that there are about 
350 million mobile phones which included Snake-game. Probably Snake is one of the most familiar and played mobile phone games. Idea of Snake is based same named video game which was released in 1970s and over the years there are published many different kind of versions of Snake. In fact Snake shows a very good which kind of mobile phone games are played and where those games are coming from. Usually mobile phone games are developed of games which are originally designed to be video games played by personal computer or video game console. Certain game cannot be said to mobile phone game only if it is possible to play game with your mobile phone. Game must take into consideration of special features and use of mobile phone. Real mobile phone game differs clearly of games which are designed to play only of portable game devices, such as Sony PSP and Nintendo DS. (Paavilainen, Korhonen \& Saarenpää 2009.)

Original reason why Nokia added Snake into mobile phones was introduce mobile phones entertainment features and data transfer which based on infrared communication. Basic idea of Snake is very simple, player mission is to give directions to snake and try to eat snacks which makes snake to grow. Snake cannot be stopped so it must be steered all the time and if snake hits to wall or itself then game is over. After Snake there was installed to mobile phones lots of other classic games, like Tetris, Pong and Breakout. All the games were two colored since colorful screens to enter the markets. In 2003 Nokia released new mobile phone model (N-Gage), which include lots of gaming features. N-Gage reminded gaming devices from 1990s, like Atari Lynx and Sega Game Gear. N-Gage was not success in markets and afterwards is has been changed to be base for one of the Nokia's smartphone series. (Paavilainen et al. 2009.)

Current mobile games are mostly designed to mobile phones just take care of restrictions and they are not designed to take into consideration of mobile phones special features. Mainly game designers are fighting with mobile phones restrictions and they are not trying to develop mobile phones special features. Usually games have very modest audiovisual because devices have such a poor sound systems. Many of games which are designed in mid 2000s (like Tower Bloxx in 2005 and Nom in 2006) were based to hit one button in right time. Like it was earlier mentioned game is not a real mobile game it does not take into consideration of mobile phone special features. For example console video games are designed very accurate taking into consideration of consoles special features and these special features designated mainly which kind of games are designed to video game consoles. (Paavilainen et al. 2009.)

A real mobile game should consider the requirement of use mobile phone device and according to these it should also consider special features of device which are connectivity, socializing and the use of cultural. Nowadays mobile phones are all the time in network and this is reason why connectivity is the most clear special feature and it is also starting point for other special features as well. Even mobile phone devices are networked all the time, playing multiplayer games is not popular. Multiplayer games are very popular when games are played by personal computer or video game console. There is no mobile game which allows playing multiplayer games in real time, in other words synchronized games, so this is of course one reason why they are not so popular. Sociability is very important to mobile games and especially communication between players should be one of the starting points to design mobile game. (Paavilainen et al. 2009.)

Connectivity and socializing are supporting and essential related to each other. Mobile phone differs from so called static devices (like personal computer and video game console) clearly in culture of use. Mobile phones are always with user not depending on time or place. Normally using mobile phone is very short-term and the use of often interrupted. (Paavilainen et al. 2009.)

Average using continuously of one application is approximately one minute at a time, but anyway average using of mobile phone in a day is about one hour. Different kind of applications are used 
What Lead to the Successful Mobile Phone Game?

- Story of birds who cannot fly but they have enough angriness

in different time of day, for example news applications are used mostly at morning, such as using game application is the most active in evenings. Communication applications are used evenly during all the day time. (Böhmer, Hecht, Schöning, Krüger \& Bauer 2011.)

Context of use mobile phones is posing challenges to game designer because in the beginning of designing they should consider many things, such as players cannot concentrate all the time to playing or playing games cannot cause too much distraction to other people whose are around the player. Playing mobile game may be interrupted by coming phone call and message. Communication is still principal use of mobile phones and it is not limited only to phone calls because communication possibilities with smartphones are versatile at which time game sessions might be very disjointed. (Paavilainen et al. 2009; Böhmer et al. 2011.)

The most restriction in smartphones is size of screen as this will affect what can be displayed in the game and game designer have to make a decision to focus on the action or the wider environment. Mobile games that are trying to put too much at once, the problem is that the player is not able to accurately detect what is going on in the game. For example in Splinter Cell-action game which is based on shooting scenes there are so much action and activities that the player is hard to detect from which direction the enemy shoots at him. (Duke \& Westwater 2011.)

Using smartphones is based on touch screens and games which are especially designed to smartphones are using very accurate when player is using touch screen. In general, the problem occurs by the game controlling the touch screen when the mobile game is developed of game which was originally developed for the console game. This kind of situation usually game designer seek to emulate control system of console games and this leads to problems where controlling game with the touch screen is very hard and even it is foreign to user who has learn to use control command which is based on touch screen. Often sport games, like Madden NFL American football suffers from problems arise the fact that the control commands are attempting to move directly from one system to another. (Duke \& Westwater 2011.)

Mobile environment is a limited factor in mobile games that game designer should keep in mind. Games played on smartphones are not suitable for those games that require several hours of gameplay. Mobile games are often played with intend to fulfill some short period of time, such as waiting to bus or train and those games that require more time are not suitable for mobile games. Angry Birds is a good example of successful mobile game, as it can be played in very short period of time and continuing play after interruption does not require any special actions. Smartphones is often played out in public places which are also likely to impact on what kind of games consumers are willing to play. (Duke \& Westwater 2011.

\section{SECRET OF THE SUCCESSFUL MOBILE PHONE GAME}

Demand for mobile phone games is very high at this time. Since the prevalence of smartphones, mobile game designers have developed the most curious and versatile mobile phone games. For consumers this is a great thing because consumers who are gaming enthusiast this offers possibility to try lots of different kinds of games. Unfortunately, the issue has another side also; consumers must wade through a jungle of games which is full of really bad games to find those few excellent mobile phone games. Some of the game designers are not able to figure out why some of mobile phone games are so popular with customers, so their self-designed mobile phone games proves to be only a waste of time and money. (Burton 2012.) 
Burton (2012) concluded that there are a number of repetitive elements which the most successful mobile phone game includes. These elements are:

simple game mechanics,

a little bit of work should follow great results,

game should proceed simply without deep tutorial or story and

levels of game should be simply and short.

Simple game mechanics is emphasized even at that stage when you are looking at profile of mobile phone gamers. Major of mobile phone gamers are average mobile phone users. So this group is full of pretty ordinary consumers whose may not be playing personal computer games or console games at all. Ordinary mobile phone gamer play games its suits for him/her and playing can be ended very quickly, so these consumers does not explicitly arrange time for playing games, such as other platform gamers may be doing. For mobile phone gamers it is important that the game can be start as soon as they want to play and also ended when they are willing to and playing a game should not require any previous experience of playing games. Thus, to be successful game it is requiring simplicity and number of commands must be minimized also. (Burton 2012.)

Playing mobile phone games should be easy to learn. It is one the key factors for the successful mobile phone game. Smartphone users are not willing to spend time to learn how to play game. Correspondingly console game players are using lots of time to modify and customize settings, but such activities are not willing to do playing mobile phone games. Getting easily and fast started is one of the most important factors. Usually, the game is available in a free version (lite version), which should be easy to learn, simple and addictive game. If the game fails in one or several of these three factors, then the game is unlike to played again and it player will not be going to download full version of it, which normally is chargeable. Anyway consumers are not willing to either invest in a very large amount of money to chargeable games. (Duke \& Westwater 2011.)

An interesting mobile phone game should offer great results with a little bit of work. Perfect example for this is the game Angry Birds. The player activates catapult by moving finger on the screen and then lifting finger on the screen will release the catapult. After effect is chaotic when there are lots of explosions, buildings collapses and birds will be released out of their cages. This satisfied players and will make them come back to playing game again. The most successful games, such as Angry Birds, Cut the Rope and Doodle Jump operates in a similar concept, there are very simple control commands and successful recipe is a simple tactic will lead to success, and that is not a coincidence. (Burton 2012; Duke \& Westwater 2011.)

At the moment one of the most popular mobile phone games is called Tamago. Idea of this game is to download an egg on the smartphone screen which is to broken by tapping the screen one million times. Next to the egg there is counter which counts every tap on and on every thousands tap will make a small crack to the egg. Tamago is considered to be very addictive game and some of the players feel this is good way to be less stressed. Some of players have already given up hope because there were nothing visible results. The simpler game may be difficult to develop.

The idea of mobile phone game concept may not be based on the complexity of the story or plot, such as it is in personal computer and console games which story is a meaningful factor. Mobile phone gamer wants to pass the level and after that player is able to end playing and come back afterwards and continue playing from the same spot. Idea of mobile phone game should be simple and possible plot may not have important role in terms of gameplay, as the player may easily ignore some important issues for the course of the game which may affect that passing a 
What Lead to the Successful Mobile Phone Game?

- Story of birds who cannot fly but they have enough angriness

level is not possible anymore. (Burton 2012.)

Mobile phone games level should be concise and passing levels should not demand too long period of time. Game designers should take into consideration that player attention to the game is short-term, because there is lots of distraction when games are usually played, for example waiting the bus or train. This is reason why levels should be designed to be short enough to catch players' attention. If levels are too long and the player progression in the game is not going on, the player will easily get bored and will not come back to play anymore. In order to create userfriendly mobile phone game it should be easy to grasp and simple control commands. All in all behind the successful mobile phone game is simplicity of all related factors to a game. (Burton 2012; Duke \& Westwater 2011.)

\section{ROVIO ENTERTAINMENT LTD AND ANGRY BIRDS}

Rovio Entertainment Ltd, better known as Rovio, is a Finnish company. It is established in 2003, when the company operated under the name Relude. In 2005 name was changed to Rovio Entertainment Ltd. Rovio is working in entertainment media business area and it is the wellknown game design company. In 2009, Rovio was close to bankruptcy before they succeeded to develop well-known Angry Birds mobile phone game. Rovio was forced to downsize the number of employees from 50 to 12. Nowadays Rovio employs over 500. Rovio's headquater is in Espoo, Finland; in addition Rovio has operation in Tampere also. The rest of world Rovio has operation in United States, China and Sweden. Rovio has three main persons who are the heart of the company. CEO is Mikael Hed and his cousin Niklas Hed is one of the co-founders. Peter Vesterbacka's official title is chief marketing officer, but he is the best known as the "Mighty Eagle". Rovio is now a world-wide company and employees represent more than 30 nationalities. (Rovio Entertainment 2013; Wikipedia 2013.)

Relude was established to contribution to success of the game King of The Cabbage World, which was developed by three students (Niklas Hed, Jarmo Väkeväinen and Kim Dikert) to mobile phone game contest, which was sponsored by Nokia and Hewlett Packard. After the contest Sumea company bought the game King of the Cabbage World and renamed it to be Mole War and the advertising it was said to be the first mobile phone game than can be played in multiplayer mode. Before Angry Birds game Rovio (and Relude) published a total of 51 games. Some of the games were resold by millions to third party (such as Namco and EA). Rovio decided to create and design their own game, which original copyrights they will own. (Cheshire 2011; Magrigal 2011.)

Angry Birds is a random puzzle game where the aim is to fling birds using catapult towards a different kind of structure which are full of different blocks and some pigs. The aim is to hit directly to pigs or to structures so that they will collapse on top of pigs. The game idea is to destroy the pigs, and usually this requires destructing the structures around the pigs. The player has available a certain number of birds, which have different special abilities, such as the one birds is able to diffuse into a plurality of birds, a one birds may be used as bomb and one bird is able to use as rocket, and so on.

Rovio's problem was not to create and design good games, but company's the biggest problem was the marketing and distribution channels. Release of the first IPhone and thereby created App Store opened a new patch to reach consumers without that they had to negotiate with every mobile phone manufacturer separately. App Store opened the whole world, because with on single contact Rovio was able to reach worldwide distribution. Rovio realized that in IPhone 
platform environment there was very high competition, but if you succeed in that environment, then you are able to extend to other smartphone platform, personal computer and consoles as well. Rovio decided to focus on designing its own mobile phone game to IPhone platform and discard the other mobile phone platforms for a while. This plan was made long before idea of Angry Birds became. The aim was to conquer App Store, but before invasion to App Store they needed to analyze IPhone user profiles very accurate. They found that target group of IPhone users are all kind of persons. So they need to create and design mobile phone game that everyone can play it. Previous Rovio had focused mainly to design sci-fi and horror games, so this new idea differ lots of previous games. Rovio decided to change game designing criteria, in which case a new game should be extensible to other application platforms, but is should work like game which is designed to IPhone. Other factor was that game should be based on the physics, it should not include introduction section or tutorial, time to start and end game should be as short as possible to maximize satisfaction when game is played short period of time. The last factor was that there should be such icon, which will allow it differentiates in App Store. (Rovio Entertainment 2013; Cheshire 2011.)

In early 2009, Rovio's game design director Jaakko lisalo introduced bird characters who did not have the legs and do not know how to fly, and they were looking very angry. Rovio's team began to wonder why the birds are so angry and even birds were very simple characters, they forced the team to think very much and they feel the characters to be somehow magical. Structure of the game and the characters evolved and changed a lot from the beginning to how consumers see them nowadays. The most significant changes during the development phase were that the birds initially responded to the colors of boxes and when the birds hit corresponding box it was crushed. Also the catapult which flings birds was added at the end of design project. Reason why there are pigs is that team needed to come up with the reason why the birds want to break down structures and idea for pigs green color appeared from news of swine flu. Green color reflects to a sick pig. Still team had to develop a story why the birds are so angry to the pigs whose seem to be very docile and wise; result for the birds' anger is that the pigs have stolen their eggs. (Cheshire 2011.)

Angry Birds was released in App Store on December 2009. The first few months was not success at all, Angry Birds was flop in the most profitable App Store markets. Rovio's strategy was not to achieve exponential invasion to the App Store, but the strategy was more of like a guerilla war to achieve better position first in smaller App Store markets. Rovio was realized that large markets would be difficult to break in, but success in the smaller countries markets did not needed to have large amounts of purchases. For example, the number one place on the Finnish App Store market needed only few hundreds purchases. The same situation was also in Sweden, Greece and Denmark. Nowadays, the UK and U.S. App Store markets are about 90 per cent of Rovio's total markets, but to get first purchase from these App Store it took to get about 30000 to 40000 downloads before from smaller markets. This amount of downloads is not particularly large, but it is still about four times what the average application normally sells. Rovio also used a help of self-publisher company (Chillingo), who had managed to take a number of applications in the App Store and Chillingo also had a good relationship with Apple. (Cheshire 2011.)

In February 2010, Apple approved the Angry Birds to UK App Stores front page in week of the game list. At the same time Rovio made a promotional video of the Angry Birds to Youtube-video service. This video was the second in history which was made of Iphone game. Today, this video has more than 17 million views. Rovio also added 42 levels to Angry Birds and released the first free version of the game. These all were released within three days and after advertising Angry Birds rose from 600th to the first place in UK App Store, and in April Angry Birds achieved the first 
What Lead to the Successful Mobile Phone Game?

- Story of birds who cannot fly but they have enough angriness

place in the United States. (Cheshire 2011.)

After the first Angry Birds release it took a few months that the game had become an international phenomenon, and today it is the all-time most popular chargeable application. Rovio has released eight successful games so far, they are; Angry Birds, Angry Birds Seasons, Angry Birds Rio, Angry Birds Space, Angry Birds Friends, Amazing Alex, Bad Piggies and Angry Birds Star Wars. Angry Birds success in mobile phone games has been expanding rapidly to other business areas also, such as entertainment, publishing and licensing activities. Angry Birds has become a beloved international brand. (Rovio Entertainment 2013; Cheshire 2011.) It is interesting to see how far birds can go without legs and ability to fly. Angry Birds have shown to whole world that with certain angry everyone is able to achieve dreams.

\section{CONCLUSIONS}

There are few main factors which reflect success or failure of mobile phone game. They all are as important and they cannot be ordered anyway. There they are just mentioned in random order. Story behind the mobile phone game should not have main or even essential role because mobile phone gamers do not have enough concentration to follow up stories or tutorials. This element has also other meaningful point because mobile phone game need to be easily ready to play; there not supposed to be long loading times and every extra tutorial will slow down to start playing. Game mechanics have to be very easy to learn. Gamers are not willing to spend their time to learn how to play game; they just want to start playing when they have time to do it. Easy game mechanics should also include easy control commands. Nowadays mobile phone games are played on smartphones and controlling games with touch screens offers many possibilities but also some restrictions. Control commands should be quite simply because as it was earlier mentioned gamers concentration is not totally focused playing games and normally gamers are doing something else at the same time. One key element to successful mobile phone game is to offer great results with a little bit of work. This element represents the main idea of mobile phone game because successful game is addictive and which is more addictive than gamer make some commands on screen and afterwards there are lots of actions on screen. Maybe the most important key element to successful game is that it should be simply and short in every way. Gamers are willing to play the game for a short-term and the must also allow some disruptions for example incoming call and incoming SMS message and the game should be easily to continue after some disruptions.

The history of mobile phone games is very short and they are at the beginning of their development. At the moment gamers are willing to play very simply games which offers just fun for short-term. Technology and innovations are developing very fast on smartphones so it may be totally different story after few years. Smartphones screen sizes are one of the biggest restrictions to develop wider stories but this may be changed very rapidly because bigger sizes screescreen seems to be trend at the moment in the most popular smartphones models, such as Samsung Galaxy S4 (screen size 5" versus Samsung Galaxy S3 screen size 4,8") which will be released soon. Nowadays consumers have lots of different kind of entertainment devices like smartphones, personal computers, tablets and game consoles. There may not even be demand to more developed games to mobile phones because consumers are willing to fill out extra times (for example waiting friends or bus) with playing mobile phone games. Then games are not needed to be complex and versatile but they need to be entertaining and addictive because it is so easy to download new game if gamer is not 
What Lead to the Successful Mobile Phone Game?

- Story of birds who cannot fly but they have enough angriness

satisfied with it. Angry Birds have become phenomenon and there have been continuum when gamers have been able to download more levels or new game without need to find totally new game. Angry Birds have also spread to other business areas too so it is real phenomena and it is still conquering new business areas all the time. Creators behind the Angry Birds have dream to become like Disney 2.0. It is a huge dream and there are lots of people who are thinking they have to be totally out of mind. Anyhow they have succeeded so far with Birds who are not able to fly or walk but they have had enough angriness to become phenomena. Within next year there are going to be more Angry Birds moving around us or there are going to be something else which will entertain us.

\section{REFERENCES}

[1] Burton, Peter (2012). What Are the Key Factors In a Successful Mobile Game? Techarta- Tech blog [online] [cited 21.3.2013]. Available at: <URL: http://www.techarta.com/5605/what-are-thekey-elements-in-making-a-mobile-game.html>.

[2] Böhmer, Matthias, Hecht, Brent, Schöning, Johannes, Krüger, Antonio \& Bauer, Gernot (2011). Falling asleep with Angry Birds, Facebook and Kindle: a large scale study on mobile application usage. Mobile HCl 2011 [online] [cited 1.3.2013], 47-56. Available at: <URL: http://dl.acm.org/ citation.cfm?id=2037383>. ISBN: 978-1-4503-0541-9.

[3] Cheshire, Tom (2011). In depth: How Rovio made Angry Birds a winner (and what's next). Wired Magazine 2011 [online] [cited 25.3.2013]. Available at: <URL: http://www.wired.co.uk/magazine/ archive/2011/04/features/how-rovio-made-angry-birds-a-winner?page=all>.

[4] Duke, Simon \& Westwater, Mark (2011). How to build a killer mobile game. .net magazine 2011 [online] [cited 21.3.2013]. Available at: <URL: http://www.netmagazine.com/features/how-buildkiller-mobile-game>.

[5] Madrigal, Alexis C. (2011). How Rovio Fought Off Bankrupcty to Make Angry Birds. The Atlantic [online] [cited 25.3.2013]. Available at: <URL: http://www.theatlantic.com/technology/ archive/2011/03/how-rovio-fought-off-bankruptcy-to-make-angry-birds/72250/>.

[6] Paavilainen, Janne, Korhonen, Hannu \& Saarenpää, Hannamari (2009). Pelaaminen matkapuhelimella nyt ja tulevaisuudessa. Pelitutkimuksen vuosikirja 2009 [online] [cited 28.2.2013], 67-81. Available at: <URL: http://research.nokia.com/files/ptvk2009-06.pdf>.

[7] Rovio Entertainment (2013). Company [online] [cited 25.3.2013]. Available at: <URL: http:// www.rovio.com/en/about-us/Company>.

[8] Wikipedia (2013). Rovio Entertainment [online] [cited 25.3.2013]. Available at: <URL: http:// fi.wikipedia.org/wiki/Rovio_Entertainment>. 